\title{
Kernos
}

Revue internationale et pluridisciplinaire de religion grecque antique

$16 \mid 2003$

Varia

\section{K.D.S. LAPATIN, Chryselephantine Statuary in the Ancient Mediterranean World}

\section{Véronique Dasen}

\section{OpenEdition \\ Journals}

\section{Édition électronique}

URL : http://journals.openedition.org/kernos/855

DOI : $10.4000 /$ kernos.855

ISSN : 2034-7871

\section{Éditeur}

Centre international d'étude de la religion grecque antique

\section{Édition imprimée}

Date de publication : 1 janvier 2003

Pagination : 385-386

ISSN : 0776-3824

Référence électronique

Véronique Dasen, «K.D.S. LAPATin, Chryselephantine Statuary in the Ancient Mediterranean World", Kernos [En ligne], 16 | 2003, mis en ligne le 14 avril 2011, consulté le 24 septembre 2020. URL : http:// journals.openedition.org/kernos/855; DOI : https://doi.org/10.4000/kernos.855 
des Chrétiens de pratiquer le culte impérial a déchaîné ou non les persécutions. L'A. se propose d'étudier ici les passages de l'Apocalypse de Jean contraires au culte impérial.

R. Parker étudie, pour sa part, "The Cult of Aphrodite Pandamos and Pontia on Cos », un culte auquel se réfèrent deux longues inscriptions du II $^{\mathrm{e}}$ siècle av. J.C. et qui apparaît aussi dans l'inscription bilingue gréco-phénicienne où Aphrodite est identifiée à Astarté. On trouvera des pages intéressantes sur les rapports entre les deux déesses et sur les éventuelles fonctions marines - fonctions secondaires - d'Astarté.

Le pied de Dionysos est le thème choisi par Renate Schlesier, en tant que symbole de l'épiphanie du dieu, notamment dans un passage de Plutarque. Enfin, c'est encore de Dionysos dont il est question dans l'essai conclusif de F.I. Zeitlin. Apollon et Dionysos sont en effet des demi-frères en tant que fils de Zeus et bien des traits les rapprochent, comme le souligna jadis Nietzsche. Il s'agit ici de comparer les récits relatifs à leur naissance, qui risquent d'être particulièrement lourds de sens lorsque l'on songe à ce que les Grecs entendaient par arcbè, début et raison de toute chose. Comme on pouvait s'y attendre, au-delà des analogies, ce sont les différences qui apparaissent comme particulièrement significatives.

Ce volume d'un très haut niveau, qui fait honneur au grand savant qu'est Versnel, se termine par un index.

Corinne Bonnet

(Université de Toulouse-Le Mirail)

Kenneth D.S. LAPATIN, Cbryselephantine Statuary in the Ancient Mediterranean World, Oxford, University Press, 2001. 1 vol. 22,5×28,5 cm, xvi +242 p., 248 fig. sur planches (Oxford Monographs on Classical Archaeology). ISBN : 0-19-815311-2.

Les statues composites d'or et d'ivoire ont compté parmi les œuvres d'art les plus admirées de l'Antiquité classique. En dépit de leur importance religieuse, artistique et économique, aucune étude d'ensemble ne leur avait été consacrée depuis le Jupiter Olympien de Quatremère de Quincy, paru en 1814. Pour combler cette lacune, l'A. s'est attaché à retracer l'évolution de leur production dans le bassin méditerranéen antique, de l'âge du bronze à l'époque romaine. Son étude repose sur près de 200 sculptures décrites dans les sources littéraires et épigraphiques. Aucune de ces cuvres ne nous est parvenue, mais des copies et des reproductions sur d'autres supports (monnaies, peinture de vase...) nous permettent de nous en faire une idée, même imparfaite. À côté de ces œuvres perdues, l'A. a répertorié plus de 50 objets très fragmentaires, dont aucun texte ne parle, mais qui étaient aussi d'une grande beauté.

Après avoir défini les problèmes posés par la nature lacunaire des sources antiques, il présente les différents types d'ivoire et d'os utilisés (hippopotame, éléphant d'Asie ou d'Afrique, mammouth ...), ainsi que les techniques de travail, de mise en forme et d'assemblage de ce matériau exotique et coûteux. Vraisemblablement, les mêmes artisans ont fabriqué les statues de culte et les objets de plus petite dimension (boîtes, peignes et autres accessoires liés aux soins cosmétiques, ornements de mobilier). Les cuvres sont passées en revue dans l'ordre chronologique, de l'âge du bronze (chap. 3), aux époques orientalisante et archaïque (chap. 4), classique (chap. 5-6), hellénistique et romaine (chap. 7). La principale fonction des sculptures chryséléphantines antiques est religieuse. Son prix élevé, sa rareté et ses qualités mimétiques firent très tôt de l'ivoire le matériau privilégié des statues de divinités. Sa couleur pâle et sa douceur évoquent la luminosité surnaturelle d'une peau divine. Allié à l'or incorruptible, il forme un ensemble précietux dont l'éclat suggère la splendeur des Olympiens. Pour éviter que l'ivoire ne sèche et se fende, des soins spéciaux sont prodigués aux statues (onction d'huile, mise en place à proximité d'un bassin rempli d'eau).

Le travail de l'ivoire, plaqué sur une âme de bois, se développe à l'époque orientalisante. Vers le milieu du $\mathbf{v i}^{\mathbf{e}}$ siècle avant $\mathrm{J}$.-C., les artistes parviennent à réaliser des statues chryséléphantines de taille plus importante, bientôt grandeur nature. Ces produits de luxe manifestent la piété, l'opulence et le pouvoir de ceux qui viennent les dédier dans les grands sanctuaires. L'émulation suscitée par les deux statues colossales de Phidias, l'Athéna Parthénos et le Zeus d'Olympie (dernier quart du ve siècle) perdure jusqu'à l'époque romaine. Les souverains hellénistiques, puis les empereurs et de riches citoyens 
traduisent leur aspiration à la divinisation en commandant leur portrait (ou ceux de leurs proches) dans ce matériau hors du commun qui évoque le corps impérissable des dieux.

Bien illustré, l'ouvrage est accompagné d'un catalogue des fragments de statues retrouvées, d'un choix de textes relatifs aux ouvres disparues (version originale et traduction), d'une bibliographie très complète et de deux appendices (une liste des statues mentionnées dans les sources littéraires et épigraphiques par site, sujet et période, ainsi qu'une discussion de la description par Pausanias de l'Athéna Areia acrolithe de Platées).

Véronique Dasen

(Université de Friboug)

Jean-Pierre Maýele Ilo, Statut mythique et scientifique de la gémellité. Essai sur la dualité, Bruxelles, Ousia, 2001. 1 vol. $14 \times 20 \mathrm{~cm}, 605$ p. (Mythes et religions). ISBN : 2-87060-083-6.

Le phénomène gémellaire occupe une place importante dans la pensée mythique universelle. Si sa fonction au sein du monde indo-européen a fait l'objet de nombreux travaux, une synthèse sur son rôle en Afrique noire manque encore. Tout en relevant cette absence, l'A. n'y répond pas de manière directe. La gémellité lui sert de moyen pour aborder de manière plus générale les rapports entre philosophie, mythe et science afin de démontrer d'une part que la fonction du mythe correspond à une démarche de la pensée qui ne diffère pas de celle de la pensée scientifique, d'autre part que " mythe et gémellité sont deux versions différentes mais superposables d'une seule et même réalité fondamentale, celle de la pensée totale" (p. 31). Afin de clarifier son propos, il crée un néologisme, la dyosynchrogénésie, pour distinguer lá réalité biologique des jumeaux de la gémellité qu'il traite comme une pensée, une logique de la « dualitude ».

L'A. s'appuie sur les réflexions de mythologues classiques pour tenter de saisir le fonctionnement de la pensée archä̈que d'Afrique noire et ses correspondances avec la pensée scientifique. Dans le $1^{\text {er }}$ chapitre, partant des travaux de M. Detienne, l'A. démontre que le mythe doit être défini autrement que comme une narration orale ou écrite, centrée sur la généalogie. Sa nature transcendentale et son universalité sont liées à sa structure, qui articule le monde visible et le monde invisible. Il est d'abord découverte de l'imbrication de ces deux niveaux, humain et divin, qui échappe à l'expérience sensorielle directe de l'homme. Le $2^{e}$ chapitre examine la notion de "vérité » ou d'« efficacité » du mythe, pour remettre en question sa dimension étiologique. Synonyme d'expérience vécue, universelle, entre l'homme et une Présence, il fonctionne comme une métaphore. Cette dimension métaphorique explique l'importance des jumeaux dans la pensée archä̈que d'Afrique noire, à laquelle l'A. consacre les $3^{\mathrm{e}}$ et $4^{\mathrm{e}}$ chapitres, mais en adoptant un biais particulier. Il confronte en les détaillant la notion de causalité naturelle ou surnaturelle dans le discours scientifique (facteurs génétiques, biochimiques, environnementaux) et clans la pensée archaïque d'Afrique noire (Dogon, Luba, Baluba, Swazi...) pour montrer que mythe et science présentent des hypothèses qui articulent les mêmes types de facteurs, connus et inconnus (le visible et l'invisible), déterminés et indéterminés (déterminisme biologique et le milieu au sens large). Dans le discours scientifique, l'élément déclencheur échappe encore, faute d'un "supplément d'âme". Dans la pensée afroarchaîque, la gémellité est définie par son extranéité. Une entité invisible décide de la grossesse de la femme et détermine la naissance de jumeaux qui représente une «ancestrophanie ", l'avènement de l'invisible dans le monde visible.

L'A. conclut par une mise en parallèle des réalités culturelles afro-archä̈ques avec celles du monde classique et indo-européen, mais sans vraiment développer la comparaison. Son souci reste de démontrer qu'il existe un rapport entre le phénomène gémellaire et le mythe qui n'est pas de l'ordre du concept mais qui relève de leur structure et de leur équilibre dynamique. La gémellité est une pensée en acte, fonctionnant comme une métaphore, c'est-à-dire comme un mythe.

Dépourvu d'index, cet ouvrage au titre prometteur n'expose pas la synthèse attendue sur les différentes fonctions symboliques de la gémellité en Afrique Noire. Réflexion philosophique, il consiste en la démonstration circonstanciée d'une hypothèse (la gémel- 